\title{
IJPPR
}

Human Journals

Research Article

September 2021 Vol.:22, Issue:2

(c) All rights are reserved by Asish Dev et al.

\section{Design and Optimization of Novel Vaginal Microsphere Gel of Clotrimazole}

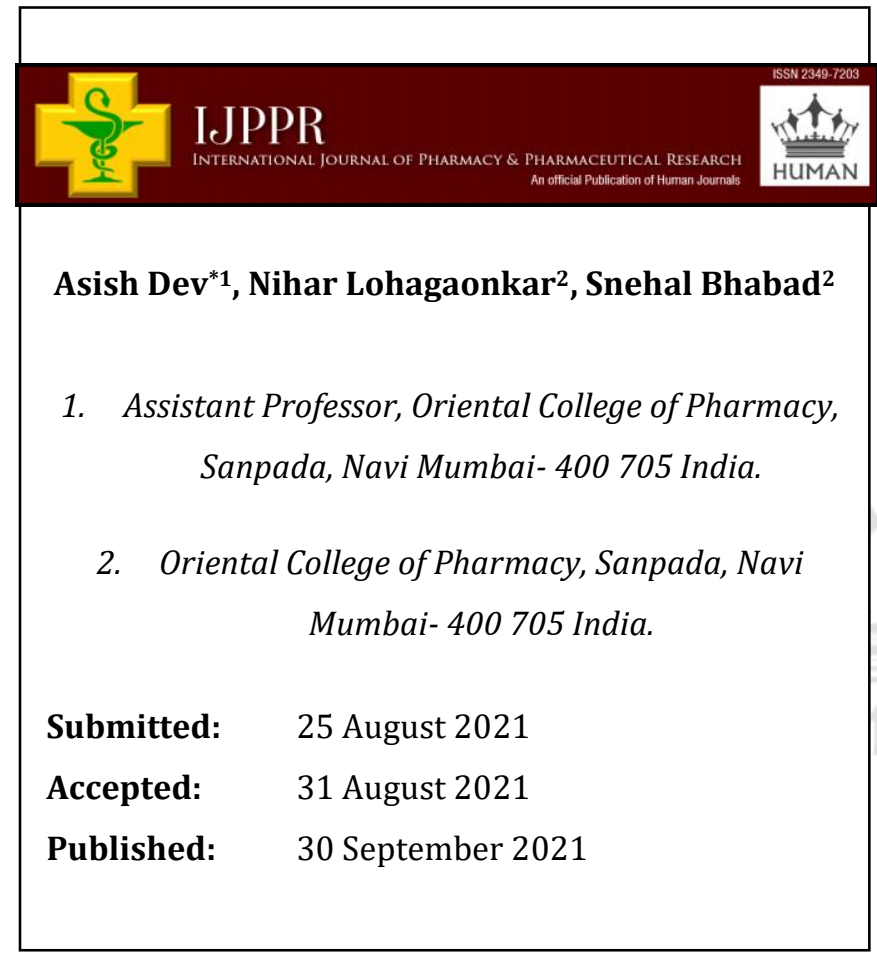

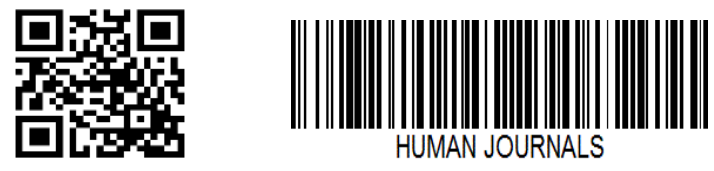

www.ijppr.humanjournals.com
Keywords: Vaginal drug delivery system, Clotrimazole, Residence time, Microspheres, SVF

\section{ABSTRACT}

The objective of the study was to develop and evaluate sustained release microsphere gel for the drug clotrimazole to be administered through the vaginal route. The effect of polymer ethylcellulose and carbopol 934 on entrapment efficiency and diffusion behavior were investigated respectively. A $3^{2}$ full-factorial design was used to optimize the formulation of Microsphere gel. Microspheres were characterized by SEM, FTIR, Entrapment efficiency, and particle size. Gels were evaluated for in-vitro drug release in simulated vaginal fluid. The microsphere loaded with clotrimazole in bioadhesive carbopol gel formulation was evaluated for various physicochemical studies and was found to be satisfactory. The rheological profile shows the gel formation at desired condition. It is evaluated for spreadability, drug content, In-vitro drug diffusion, stability study, and bioadhesive study. It may be concluded that spray drying is a suitable method for microsphere preparation and microsphere gel can be used as a novel drug delivery system to prolonge release of clotrimazole for vaginal candidiasis. 


\section{INTRODUCTION:}

The vagina has been used for a long time as a route for drug delivery, traditionally to obtain a local pharmacological effect, although some systemic drug absorption was observed. Several drug classes have been administered through the vaginal mucosa such as antimicrobials, labor inducers, spermicides, and sexual hormones. Until the 1920s the vagina was considered to be an organ incapable of absorbing drugs systematically. Although most are indicated for the treatment of local conditions, a number of them can achieve sufficient serum levels to have systemic effects [1,2]. The vaginal mucosa permeability proved to be higher to some substances such as water, 17-estradiol, arecoline, and arecaidine when compared to the intestinal mucosa $[3,4]$. The permeation mechanism to most substances is simple diffusion, where hydrophobic substances are preferentially absorbed by the intracellular route, while hydrophilic ones are preferentially absorbed by pores present in the vaginal mucosa [5]. Ideal vaginal drug delivery systems should be easy to use, discreet, of reversible application, painless to the patient, cost-effective, widely available, and safe for continuous administration. It should also allow self-administration, with minimal interference with body functioning and daily life, and obtain high bioavailability with other medications [6].

The advantages of administration by the vaginal route are the avoidance of hepatic first-pass metabolism, a reduction in the incidence and severity of gastrointestinal side effects, a decrease in hepatic side effects of drugs such as steroids, and overcoming of pain, tissue damage, and probable infection observed with parental routes [7]. Vaginal drug delivery systems include a large variety of pharmaceutical dosage forms such as semi-solids, tablets, capsules, pessaries, liquid preparations, vaginal films, vaginal rings, foams, and tampons. Most widely used semi-solid preparations for vaginal drug delivery include creams, ointments, and gels [8]. The main advantages of semi-solid preparations are acceptability, feasibility, and low cost. On the other hand, messiness, discomfort, and leakage are its main disadvantages [9].

\section{MATERIALS AND METHODS}

\section{MATERIALS}

Clotrimazole was obtained from Sun Pharma pharmaceuticals Pvt. Ltd. Ethylcellulose, Carbopol 934P, Bovine serum albumin, and lactic acid obtained from Microlabs, Mumbai, India. All other chemicals and solvents used in the experiments were of analytical grade. 


\section{FORMULATION DEVELOPMENT}

Microspheres were prepared by the spray-drying method. The drug-polymer (clotrimazoleEthyl cellulose) combination is dissolved in ethanol at room temperature to obtain a feed solution. Clotrimazole-loaded microspheres were obtained by spray drying the feed solution with a spray dryer. The dried microsphere was obtained. Carbopol 934 polymer was dispersed in distilled water in which glycerol was formerly added mixture was stirred until thickening takes placed and neutralized by dropwise addition of triethanolamine and add microsphere equivalent to $100 \mathrm{mg}$ into it and mix well to get microsphere gel.

Table No 1: - Composition of microsphere gel formulations.

\begin{tabular}{|l|c|c|c|c|c|c|c|c|c|}
\hline Contents & F1 & F2 & F3 & F4 & F5 & F6 & F7 & F8 & F9 \\
\hline Clotrimazole (g) & 1 & 1 & 1 & 1 & 1 & 1 & 1 & 1 & 1 \\
\hline Ethyl cellulose (g) & 1 & 1.5 & 2 & 1 & 1.5 & 2 & 1 & 1.5 & 2 \\
\hline Ethanol (q.s.) & q.s. & q.s. & q.s. & q.s. & q.s. & q.s. & q.s. & q.s. & q.s. \\
\hline Carbopol 934 (g) & 0.5 & 0.5 & 0.5 & 1 & 1 & 1 & 1.5 & 1.5 & 1.5 \\
\hline Distilled water (g) & 88 & 88 & 88 & 88 & 88 & 88 & 88 & 88 & 88 \\
\hline Glycerine (g) & 10 & 10 & 10 & 10 & 10 & 10 & 10 & 10 & 10 \\
\hline $\begin{array}{l}\text { Triethanolamine } \\
\text { (q.s.) }\end{array}$ & q.s. & q.s. & q.s. & q.s. & q.s. & q.s. & q.s. & q.s. & q.s. \\
\hline
\end{tabular}

\section{Preformulation study:}

It is essential to ensure the development of stable, effective, and safe dosage forms.

\section{Solubility analysis:}

Solubility analysis is made by adding solute in small incremental amounts to fixed volumes of solvents such as distilled water, ethanol, methanol, and propylene glycol.

\section{Melting point:}

The melting point was estimated by the open capillary method.

\section{Confirmation of drug using UV-VIS Spectrophotometric method:}

Simulated vaginal fluid 4.5 was selected for preparation of the calibration curve. 
$100 \mathrm{mg}$ of crude extract was dissolved in Simulated vaginal fluid and diluted up to $100 \mathrm{ml}$ to get a concentration of $1000 \mathrm{ppm}$ which is treated as stock solution. This stock solution was diluted further to get different concentrations. Resultant solutions were scanned for $\lambda$ max in the range of 200-400 nm using a UV spectrophotometer.

\section{Calibration curve:}

Clotrimazole of about $100 \mathrm{mg}$ was dissolved in a sufficient amount of SVF and make up the volume to $100 \mathrm{ml}$ to make a concentration of $1000 \mu \mathrm{g} / \mathrm{ml}$. The above solution was diluted suitably to get a concentration of $200 \mu \mathrm{g} / \mathrm{ml}$. From this solution, a working standard solution of $20-100 \mu \mathrm{g} / \mathrm{ml}$ was prepared by dilution with SVF. The absorbance of the solution was measured at $264 \mathrm{~nm}$ against the reagent blank. Calibration curves were prepared.

\section{EVALUATION OF MICROSPHERES:}

Particle Size Analysis: The particle size is determined by using a simple microscope at the laboratory level.

Scanning Electron Microscopy (SEM): Surface characteristic of the microsphere was analyzed by scanning electron microscopy (SEM) different resolutions of the samples were taken.

Entrapment efficiency: The EE was determined by extraction of $100 \mathrm{mg}$ of the microsphere with a sufficient amount of methanol, followed by filtration and appropriate dilution with SVF, the resultant concentration was determined at $264 \mathrm{~nm}$ using UV/VIS spectrophotometer.

Percent yield: The percent yield was determined according to the total final weight of the microsphere (actual yield) and the total original weight of clotrimazole and polymer (theoretical yield).

\section{EVALUATION OF MICROSPHERE GEL:}

Measurement of viscosity: The viscosity of the developed gel formulation was determined by using a Brookfield viscometer with spindle No. 64. 
Measurement of pH: The $\mathrm{pH}$ of the developed microsphere gel was determined using a digital pH meter. $1 \mathrm{~g}$ of gel was dissolved in $100 \mathrm{ml}$ of water and kept aside for 2 hours. The measurement of $\mathrm{pH}$ of each formulation is done in triplicate and average values are calculated.

Spreadability: Spreadability refers to the extent of the area to which gel readily spreads on application. It is determined by a wooden block and glass slide apparatus. The time (Sec) taken by two slides to slip off from gel which is placed in between the slides under the direction of a certain load is expressed as spreadability. The smaller the time taken for the separation of two slides, the better will be the spreadability. Spreadability is calculated by using the formula: $\mathrm{S}=$ M.L / T Where, $\mathrm{S}=$ Spreadability $\mathrm{M}=$ Weight tide to the upper slide $\mathrm{L}=$ Length of a glass slide $\mathrm{T}=$ Time taken to separate the slides from each other $\mathrm{S}=\mathrm{M} . \mathrm{L} / \mathrm{T}$

Drug Content Determination: Clotrimazole content in the gel was measured by dissolving a known quantity of gel in the solvent (ethanol) by sonication. Absorbance was measured at $264 \mathrm{~nm}$ using a UV/VIS spectrophotometer.

Compatibility studies by FT-IR: Fourier transform instrument determines the absorption spectrum for a compound in the common range of 4000 to $400 \mathrm{~cm}^{-1}$. Preparation of samples: A baseline correction was made using dried KBR. A weighed amount of the drug was mixed thoroughly with potassium bromide (dried at $40-50^{\circ} \mathrm{C}$ ) which was then compressed under 10ton pressure in a hydraulic press to form a pellet which was then scanned from 4000-400 $\mathrm{cm}^{-1}$.

In-vitro Release/Permeation Studies: The in-vitro drug release was carried out using a modified Franz diffusion cell. The formulation was applied on a cellophane membrane (which was previously soaked in simulated vaginal fluid of $\mathrm{pH} 4.5$ for 24 hours) which was sandwiched between the donor and receptor compartment of the Franz diffusion cell. Simulated Vaginal Fluid was used as dilution media. The temperature of the cell was maintained at $37 \pm 0.2^{\circ} \mathrm{C}$ by keeping it in a water bath. This whole assembly was kept on a magnetic stirrer and the solution was stirred continuously using a magnetic bead at $50 \mathrm{rpm}$. The samples (1 ml aliquots) were withdrawn at suitable time intervals and analyzed for drug content by UV/VIS spectrophotometer at $264 \mathrm{~nm}$ after appropriate dilution.

Antifungal activity: Antifungal activity of clotrimazole bulk powder and clotrimazole microsphere gel was evaluated against Candida albicans j1012 by using the cup plate 
method. A volume of $20 \mathrm{ml}$ of sterilized agar media was dispersed into three different sterilized Petri dishes and allowed to solidify. In each petri dish an $8 \mathrm{~mm}$, the bore was made using a borer at the center of the petri dish. Each bore was loaded with equal quantities of the clotrimazole bulk powder, clotrimazole microsphere gel. Petri dishes were incubated at a temperature of $37^{\circ} \mathrm{C}$ for $24 \mathrm{hrs}$ to allow the growth of microorganisms to take place. The zone of inhibition produced by the clotrimazole bulk powder and clotrimazole microsphere gel towards the test organism was measured $(\mathrm{mm})$ in the petri dish and photographed.

In-vitro bioadhesive study: The bioadhesive potential of the clotrimazole microsphere gel was evaluated in comparison with the marketed clotrimazole gel (candid-V gel) by an in-vitro method. $1 \% \mathrm{w} / \mathrm{w}$ agar plate was prepared in $\mathrm{pH} 4.5 \mathrm{SVF} .50 \mathrm{mg}$ was placed at the center of the plate. After $5 \mathrm{~min}$, the agar plate was attached to a USP disintegration apparatus and moved up and down in $\mathrm{pH} 4.5 \mathrm{SVF}$ at $37 \pm 1^{\circ} \mathrm{C}$. The sample on the plate was deep into the solution at the lowest point and was out of the solution at the highest point. The residence time of the trial samples on the plate was noted visually.

Stability studies: The optimized formulation was prepared, packed in aluminium collapsible tubes, and subjected to stability studies at $40^{\circ} \mathrm{C} / 75 \% \mathrm{RH}$ for a period of 3 months. Samples were withdrawn at 1 month time interval and evaluated for physical appearance, $\mathrm{pH}$, rheological properties, drug content, and drug release.

Kinetic studies and release mechanism: To investigate this in-vitro drug release rate, numerous kinetic models have been used. The mathematical modeling of the data is divided into mechanistic realistic models and empirical and semi-empirical models. A mechanistic, realistic mathematical model is built on equations that describe real phenomena, e.g. mass transport by diffusion, dissolution of drug and/or excipient particles, and/or the transition of a polymer from the glassy to the rubbery state. These equations form the basis of mathematical theory. In the empirical models, mathematical treatment is purely descriptive and not based on any physical, chemical, and/or biological phenomena. Consequently, no or very limited insight into the underlying drug release mechanisms can be gained. 
www.ijppr.humanjournals.com

\section{RESULTS AND DISCUSSION:}

Preformulation studies results:

Solubility analysis:

Table No. 2: Solubility of drug clotrimazole

\begin{tabular}{|c|l|c|}
\hline Sr. No. & \multicolumn{1}{|c|}{ Solvent } & Solubility behavior \\
\hline 1 & Distilled water & Insoluble \\
\hline 2 & Ethanol & Soluble \\
\hline 3 & Methanol & Soluble \\
\hline 4 & Propylene glycol & Soluble \\
\hline
\end{tabular}

Determination of melting point:

The melting point of the clotrimazole was found to be $153^{\circ} \mathrm{C}$.

Confirmation of drug using UV-VIS Spectrophotometric method:

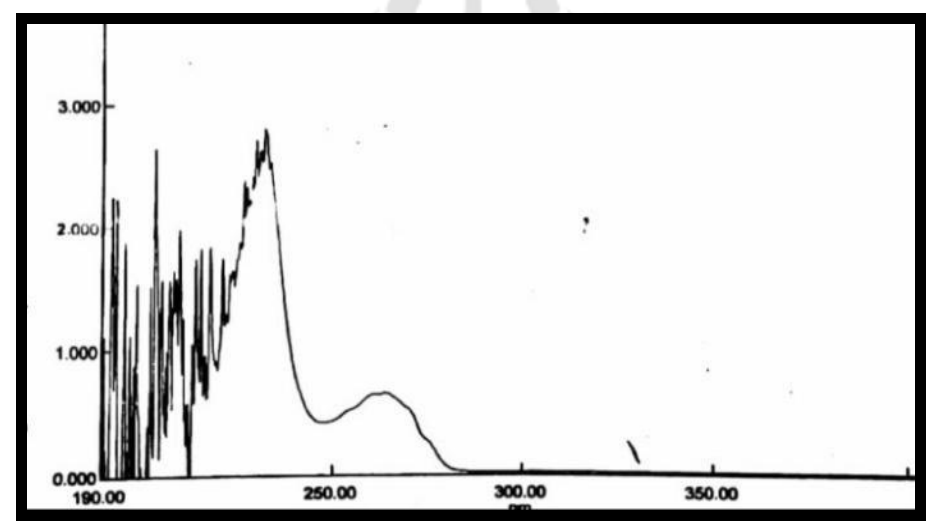

Figure No. 1: UV spectra of clotrimazole using simulated vaginal fluid

The $\lambda$ max value was found to be $264 \mathrm{~nm}$. 
www.ijppr.humanjournals.com

\section{Calibration curve:}

Table No. 3: Calibration curve of clotrimazole using simulated vaginal fluid:

\begin{tabular}{|c|c|c|}
\hline Sr. No. & Concentration $(\mu \mathrm{g} / \mathrm{ml})$ & Absorbance \\
\hline 1 & 0 & 0 \\
\hline 2 & 20 & 0.098 \\
\hline 3 & 40 & 0.197 \\
\hline 4 & 60 & 0.292 \\
\hline 5 & 80 & 0.395 \\
\hline 6 & 100 & 0.492 \\
\hline
\end{tabular}

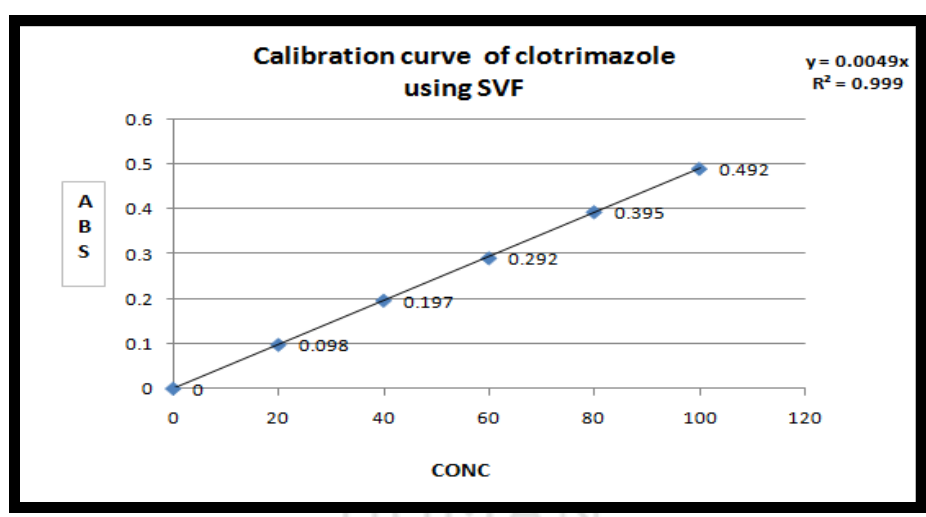

Figure No. 2: Calibration curve value using SVF (Simulated Vaginal Fluid)

\section{EVALUATION OF MICROSPHERES:}

Particle size analysis:

\section{Microscopic method:}

The Smartphone image displaying micro-sized particles of the clotrimazole-loaded microsphere was visualized by a simple compound microscope for the surface morphology. Results indicate a micro-sized range microsphere. 


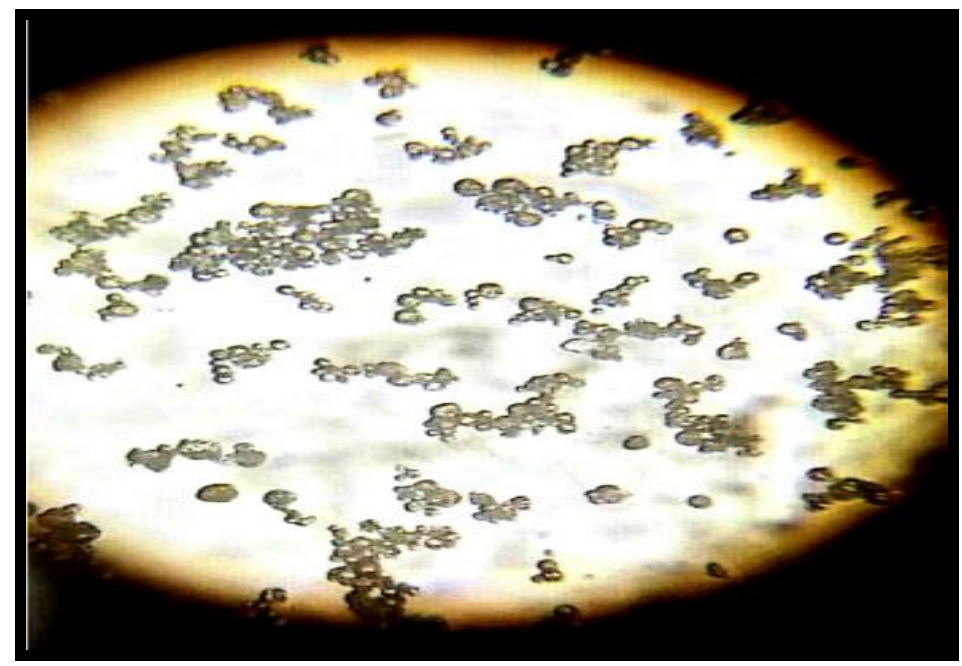

Figure No. 3: Particle size analysis by microscopic method

\section{Scanning Electron Microscopy (SEM):}

Surface characteristic of the microsphere was analyzed by scanning electron microscopy (SEM) different resolutions of the samples were taken.

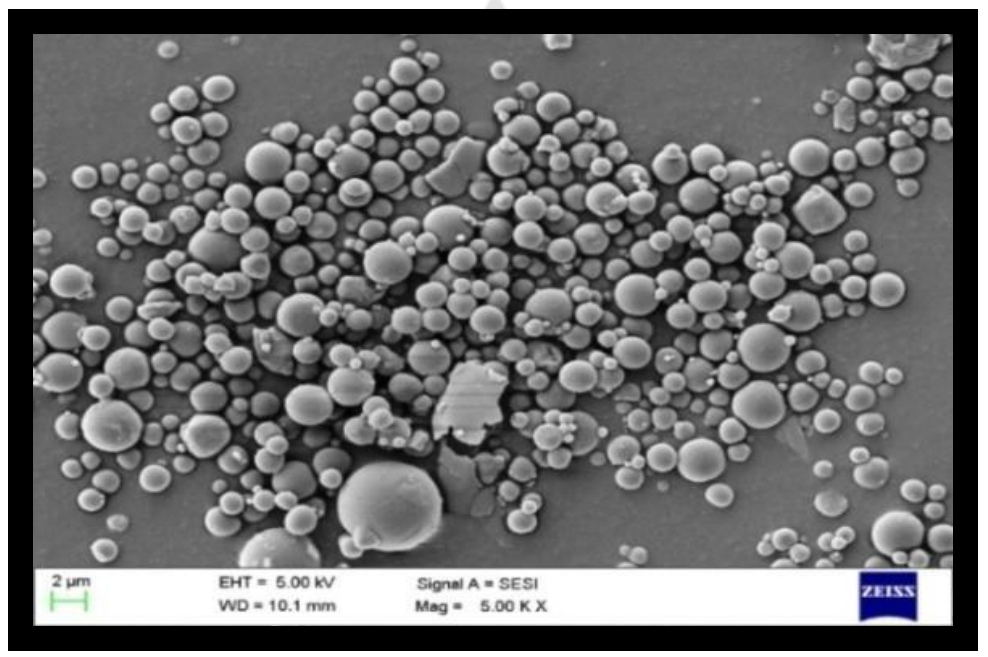

Figure No. 4: SEM of batch F9 
www.ijppr.humanjournals.com

\section{Entrapment efficiency:}

Table No. 4: Entrapment efficiency of F1 - F9 Batches

\begin{tabular}{|c|c|c|c|c|c|c|c|c|c|}
\hline Batches & F1 & F2 & F3 & F4 & F5 & F6 & F7 & F8 & F9 \\
\hline Entrapment & & & & & & & & & \\
Efficiency & 86.53 & 90.30 & 94.06 & 86.92 & 89.09 & 94.85 & 87.56 & 91.55 & 95.08 \\
$(\%)$ & $\%$ & $\%$ & $\%$ & $\%$ & $\%$ & $\%$ & $\%$ & $\%$ & $\%$ \\
\hline
\end{tabular}

Percent yield:

Table No. 5: Percent yield of F1 - F9 Batches

\begin{tabular}{|c|c|c|c|c|c|c|c|c|c|}
\hline Batches & F1 & F2 & F3 & F4 & F5 & F6 & F7 & F8 & F9 \\
\hline $\begin{array}{c}\text { Percent } \\
\text { Yield } \\
(\%)\end{array}$ & $45 \%$ & $64 \%$ & $73.33 \%$ & $44.5 \%$ & $60 \%$ & $76.66 \%$ & $46 \%$ & $68 \%$ & $80.66 \%$ \\
\hline
\end{tabular}

\section{EVALUATION OF MICROSPHERE GEL:}

Viscosity: All the formulations were checked for Viscosity and the data is given in Table No. 6.

pH determination: Skin compatibility is the primary requirement for a good topical formulation. It was found that the $\mathrm{pH}$ of all formulations was in the range of $\mathrm{pH} 3.5$ to 4.2 (Table No. 6).

\section{Spreadability studies:}

If the spreadability value is more, it would be properly spread over the skin which is more beneficial as per patient compliance concerns. All the formulations were checked for spreadability and the data is given in Table No. 6. F9 shows the best spreadability.

\section{Drug content determination:}

The drug content of all the formulations was found as per the method mentioned in the methodology section. The drug content of all the formulations was found to be in the range of $82-90 \%$ as indicated in Table No. 6 . 
www.ijppr.humanjournals.com

Table No. 6: Characterization of Formulations for Viscosity, pH, Spreadability, Drug content.

\begin{tabular}{|c|c|c|c|c|c|c|c|c|c|}
\hline $\begin{array}{c}\text { Batches } \\
\text { Results }\end{array}$ & F1 & F2 & F3 & F4 & F5 & F6 & F7 & F8 & F9 \\
\hline Viscosity (cps) & 22341 & 18558 & 28465 & 18956 & 26589 & 29658 & 18921 & 21256 & 30567 \\
\hline pH & 3.5 & 3.9 & 3.3 & 4.0 & 3.7 & 3.4 & 3.2 & 3.8 & 4.2 \\
\hline $\begin{array}{c}\text { Spreadability } \\
\text { (gm.cm/sec) }\end{array}$ & 11.67 & 10.76 & 11.89 & 12.08 & 10.98 & 11.78 & 11.56 & 11.43 & 12.86 \\
\hline $\begin{array}{c}\text { Drug content } \\
(\%)\end{array}$ & 82.08 & 84.30 & 89.20 & 82.30 & 88.00 & 89.65 & 83.80 & 85.96 & 90.36 \\
\hline
\end{tabular}

Compatibility studies by FTIR:

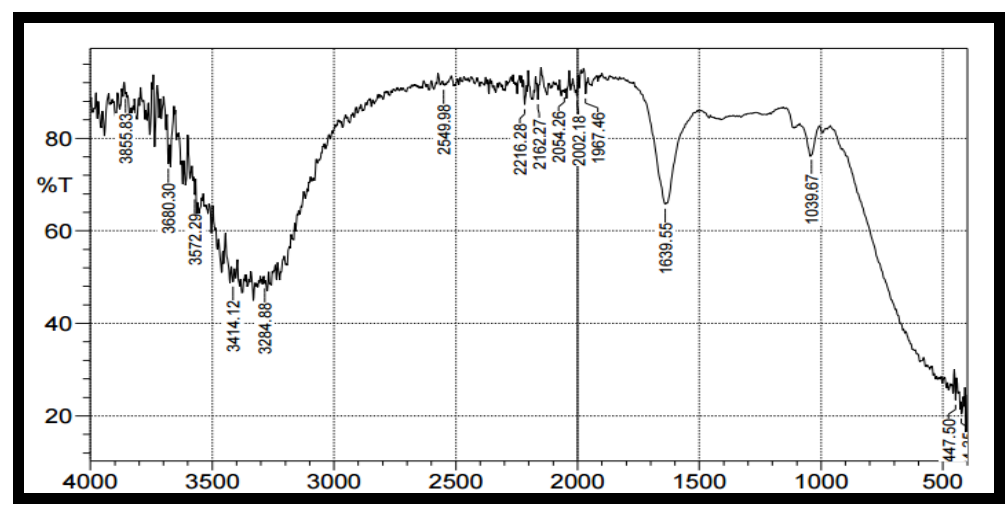

Figure No. 5: FTIR of Formulation 
www.ijppr.humanjournals.com

In-vitro drug permeation of formulations:

Table No. 7: In-vitro drug release of F1 to F9 batches and Marketed formulation shows percent cumulative drug release

\begin{tabular}{|c|c|c|c|c|c|c|c|c|c|c|}
\hline $\begin{array}{c}\text { Time } \\
\text { (hrs) }\end{array}$ & F1 & F2 & F3 & F4 & F5 & F6 & F7 & F8 & F9 & Vandid \\
\hline $\mathbf{1}$ & 7.55 & 8.12 & 9.31 & 10.97 & 7.97 & 10.20 & 9.38 & 12.40 & 8.78 & 8.95 \\
\hline $\mathbf{2}$ & 13.90 & 19.85 & 16.16 & 16.21 & 13.80 & 11.13 & 10.24 & 13.52 & 9.58 & 12.36 \\
\hline $\mathbf{3}$ & 21.74 & 27.08 & 24.39 & 25.37 & 19.33 & 21.41 & 19.10 & 22.58 & 20.92 & 14.56 \\
\hline $\mathbf{4}$ & 25.56 & 33.14 & 29.56 & 30.48 & 27.83 & 29.79 & 30.42 & 33.23 & 34.10 & 16.52 \\
\hline $\mathbf{5}$ & 32.02 & 35.08 & 35.09 & 35.28 & 35.49 & 39.18 & 38.99 & 41.36 & 51.59 & 25.65 \\
\hline $\mathbf{6}$ & 37.07 & 40.25 & 46.69 & 42.19 & 50.90 & 45.60 & 45.86 & 53.21 & 65.53 & 48.36 \\
\hline $\mathbf{7}$ & 41.64 & 49.58 & 59.42 & 51.35 & 64.88 & 63.89 & 59.29 & 70.47 & 76.95 & 62.34 \\
\hline $\mathbf{8}$ & 48.86 & 60.11 & 71.05 & 58.23 & 77.35 & 80.73 & 65.21 & 89.79 & 91.33 & 77.86 \\
\hline
\end{tabular}

In-vitro drug release of batch F1 to F9:

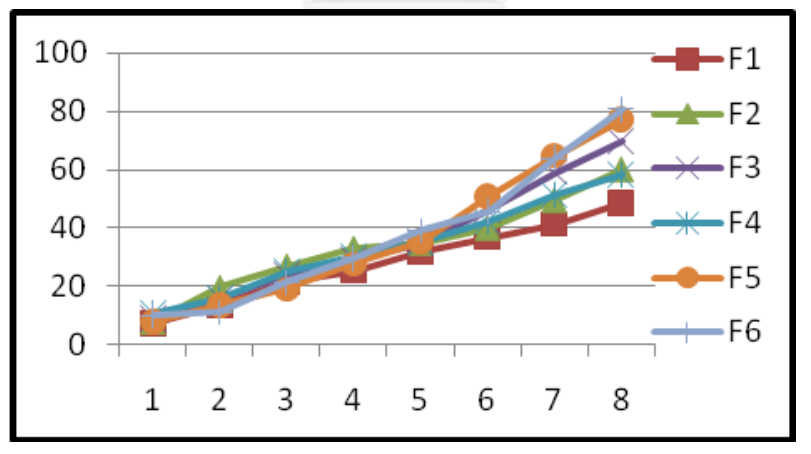

Figure No. 6: In-vitro drug release of batch F1 to F6

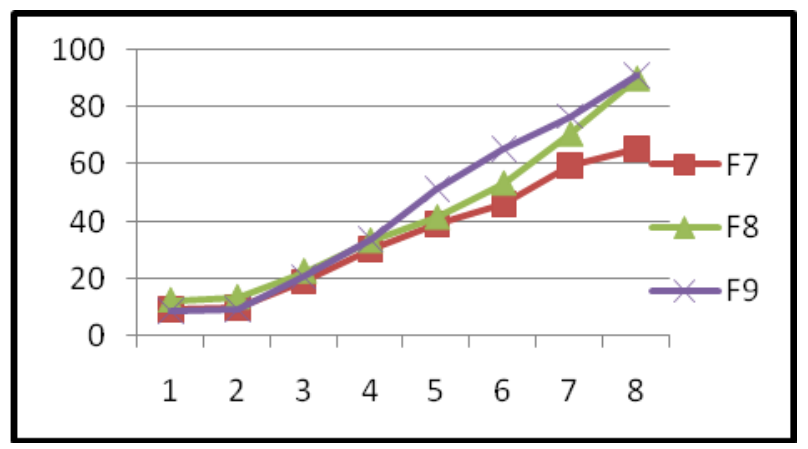

Figure No. 7: In-vitro drug release of batch F7 to F9 
www.ijppr.humanjournals.com

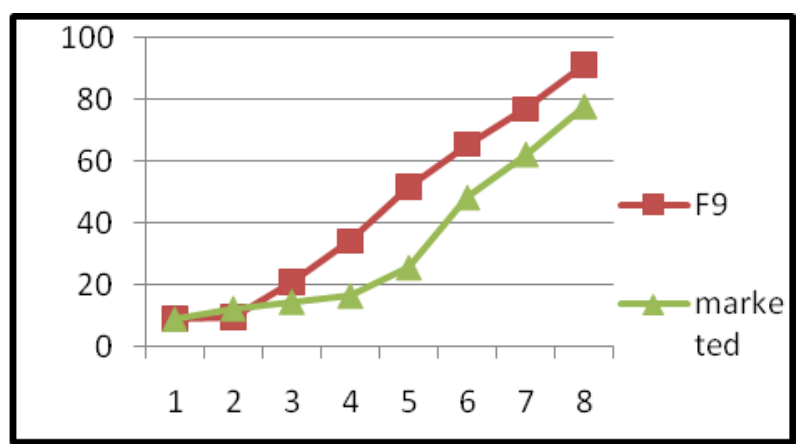

Figure No. 8: Drug release of optimized batch F9 vs marketed gel

\section{Antifungal study:}

Table No 8: Zone of inhibition

\begin{tabular}{|l|c|}
\hline Samples & Zone of inhibition $(\mathbf{m m})$ \\
\hline Clotrimazole bulk powder & 19.5 \\
\hline Clotrimazole microsphere gel & 19.3 \\
\hline
\end{tabular}

Stability studies: Optimized formulation was packed in aluminum collapsible tubes and subjected to stability studies at $40^{\circ} \mathrm{C} / 75 \%$ RH for 3 months.

Table No. 9: Stability study of Optimized F9 batch

\begin{tabular}{|l|c|c|c|}
\hline $\begin{array}{l}\text { Evaluation } \\
\text { parameters }\end{array}$ & $\mathbf{1}^{\text {st }}$ month & $\mathbf{2}^{\text {nd }}$ month & $\boldsymbol{3}^{\text {rd }}$ month \\
\hline $\mathrm{pH}$ & 4.3 & 4.2 & 4.2 \\
\hline Viscosity & 30556 & 30553 & 30521 \\
\hline Spreadability & 12.56 & 12.68 & 12.69 \\
\hline In-vitro drug release & 92.67 & 92.43 & 92.40 \\
\hline Drug content & 90.02 & 90.33 & 90.52 \\
\hline
\end{tabular}

\section{In-vitro drug release kinetics:}

The kinetics were studied by fitting the data in various kinetic models like zero order, first order, and the results are shown in Table No. 10. When the $\mathrm{R}^{2}$ values of regression plots were considered, $\mathrm{R}^{2}$ values of zero-order plots were found to be higher. Hence it is evident that the drug release from all formulations followed zero-order kinetics. 
www.ijppr.humanjournals.com

Table No. 10: Drug release kinetics of optimized batch

\begin{tabular}{|l|c|}
\hline Release kinetic model & Regression coefficient \\
\hline Zero order & 0.9807 \\
\hline First order & 0.8665 \\
\hline Higuchi model & 0.9315 \\
\hline Hixson-crowell model & 0.9278 \\
\hline Korsmeyer-peppas model & 0.6484 \\
\hline
\end{tabular}

\section{CONCLUSION:}

The microsphere was prepared by using the spray drying technique. Bioadhesive gel was prepared by incorporating drug-loaded microspheres into bioadhesive polymer Carbopol 934. Using $3^{2}$ full factorial designs, the effect of the interaction of two independent variables $\mathrm{X}_{1}$ (ethylcellulose) and $\mathrm{X}_{2}$ (Carbopol 934) on Entrapment and drug release was studied and optimized. Further, the study showed that all two dependent variables had a significant effect on the selected responses. F9 batch was selected as an optimized batch as all evaluation parameters results were satisfactory. Stability data was recorded over 3 months and observed that formulations were stable. Studies revealed that the optimized batch follows Zero-order release kinetics due to the highest value of regression coefficient $\left(\mathrm{R}^{2}=0.9807\right)$. The polymers affect the release of the drug, F9 batch showed $91.33 \%$ drug release within 8 hrs whereas the marketed product showed $77.86 \%$ drug release. The microsphere gel was characterized by in-vitro drug release and antifungal activity. The bioadhesive potential of clotrimazole microsphere gel and the marketed formulation was evaluated by the in-vitro method and the Retention time shown by clotrimazole microsphere gel was significantly higher than marketed formulation, this is due to the presence of Carbopol because its bioadhesiveness is maximum at vagina $\mathrm{pH}$. From that, it can be concluded that the clotrimazole microsphere gel might be a better option over conventional formulation. It may be concluded that spray drying is a suitable method for microsphere preparation and microsphere gel can be used as a novel drug delivery system for prolonged release of clotrimazole for vaginal candidiasis. 


\section{REFERENCES:}

[1] Alexander N, Baker E, Kaptein M, Karck U, Miller L, Zampaglione E. Why consider vaginal drug administration?. Fertility and Sterility. 2004;82(1):1-12.

[2] Song Y, Wang Y, Thakur R, Meidan V, Michniak B. Mucosal Drug Delivery: Membranes, Methodologies, and Applications. Critical Reviews in Therapeutic Drug Carrier Systems. 2004;21(3):195-256.

[3] van der Bijl P, van Eyk A. Comparative in vitro permeability of human vaginal, small intestinal and colonic mucosa. International Journal of Pharmaceutics. 2003;261(1-2):147-152.

[4] vanEyk A, van der Bijl P. Porcine vaginal mucosa as an in vitro permeability model for human vaginal mucosa. International Journal of Pharmaceutics. 2005;305(1-2):105-111.

[5] Sassi A, McCullough K, Cost M, Hillier S, Rohan L. Permeability of tritiated water through human cervical and vaginal tissue. Journal of Pharmaceutical Sciences. 2004;93(8):2009-2016.

[6] Garg S, Tambwekar K, Vermani K, Kandarapu R, Garg A, Waller D et al. Development Pharmaceutics of Microbicide Formulations. Part II: Formulation, Evaluation, and Challenges. AIDS Patient Care and STDs. 2003;17(8):377-399.

[7] Vermani K, Garg S. The scope and potential of vaginal drug delivery. Pharmaceutical Science \& Technology Today. 2000;3(10):359-364.

[8] Prista L.N, Alves A.C, Morgado R, 1996. TecnologiaFarmaceutica, vol.^ III, 4th ed. Fundac saoCalousteGulbenkian, Lisboa. 1585-1594.

[9] Hussain A, Ahsan F. The vagina as a route for systemic drug delivery. Journal of Controlled Release. 2005;103(2):301-313.

[10]Raj H, Sharma S, Sharma A, Verma K, Chaudhary A. A Novel Drug Delivery System: Review on Microspheres. Journal of Drug Delivery and Therapeutics. 2021;11(2-S):156-161.

[11]Raj H, Sharma A, Sharma S, Verma K, Chaudhary A. Mucoadhesive Microspheres: A Targeted Drug Delivery System. Journal of Drug Delivery and Therapeutics. 2021;11(2-S):150-155.

[12] Kadam NR and Suvarna V. Microspheres: A brief Review. Asian Journal of Biomedical and Pharmaceutical Sciences, 2015; 5(47):13-19.

[13] Guterres S, Frank L, Sandri G, D’Autilia F, Contri R, Bonferoni M et al. Chitosan gel containing polymeric nanocapsules: a new formulation for vaginal drug delivery. International Journal of Nanomedicine. $2014 ;: 3151$.

[14] Su Y, Zhang B, Sun R, Liu W, Zhu Q, Zhang X et al. PLGA-based biodegradable microspheres in drug delivery: recent advances in research and application. Drug Delivery. 2021;28(1):1397-1418.

[15] Ekama S, Ilomuanya M, Azubuike C, Bamidele T, Fowora M, Aina O et al. Mucoadhesive Microspheres of Maraviroc and Tenofovir Designed for Pre-Exposure Prophylaxis of HIV-1: An in vitro Assessment of the Effect on Vaginal Lactic Acid Bacteria Microflora. HIV/AIDS - Research and Palliative Care. 2021; Volume 13:399-413.

[16] Bachhav Y, Patravale V. Microemulsion-Based Vaginal Gel of Clotrimazole: Formulation, In Vitro Evaluation, and Stability Studies. AAPS PharmSciTech. 2009;10(2).

[17] Saralidze K, Koole L, Knetsch M. Polymeric Microspheres for Medical Applications. Materials. 2010;3(6):3537-3564.

[18] MICROSPHERES FOR CONTROLLED RELEASE DRUG DELIVERY: AN OVERVIEW ON PREPARATION METHODS AND CHARACTERISATION. International Journal of Biology, Pharmacy and Allied Sciences. 2020;9(4).

[19] Chen L, Ahmed A, Deng Y, Cao D, Du H, Cui J et al. Novel triptorelin acetate-loaded microspheres prepared by a liquid/oil/oil method with high encapsulation efficiency and low initial burst release. Journal of Drug Delivery Science and Technology. 2019;54:101390.

[20] Kalita B, Saikia K, Kalita B. FORMULATION AND EVALUATION OF METRONIDAZOLE MICROSPHERES-LOADED BIOADHESIVE VAGINAL GEL. Asian Journal of Pharmaceutical and Clinical Research. 2017;10(3):418. 